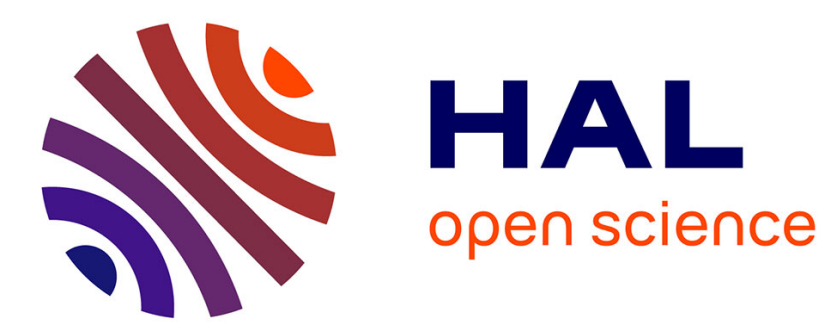

\title{
España en Viena: una academia literaria "a la española" en la corte imperial en tiempos de la emperatriz Margarita Teresa
}

\author{
Alain Begue
}

\section{- To cite this version:}

Alain Begue. España en Viena: una academia literaria "a la española" en la corte imperial en tiempos de la emperatriz Margarita Teresa. "Doctos libros juntos": homenaje al profesor Ignacio Arellano, 2018. hal-02522928

\author{
HAL Id: hal-02522928 \\ https://hal.science/hal-02522928
}

Submitted on 14 Apr 2020

HAL is a multi-disciplinary open access archive for the deposit and dissemination of scientific research documents, whether they are published or not. The documents may come from teaching and research institutions in France or abroad, or from public or private research centers.
L'archive ouverte pluridisciplinaire HAL, est destinée au dépôt et à la diffusion de documents scientifiques de niveau recherche, publiés ou non, émanant des établissements d'enseignement et de recherche français ou étrangers, des laboratoires publics ou privés. 


\title{
ESPAÑA EN VIENA: UNA ACADEMIA LITERARIA «A LA ESPAÑOLA» EN LA CORTE IMPERIAL EN TIEMPOS DE LA EMPERATRIZ MARGARITA TERESA
}

\author{
Alain Bègue \\ FoReLL-CELES XVII-XVIII, Université de Poitiers
}

\begin{abstract}
El siglo XVII, particularmente en su segunda mitad, vio florecer y multiplicarse las manifestaciones literarias públicas o privadas de las que las academias suponen un fruto singular por su doble impronta tanto historiográfica como socioliteraria ${ }^{1}$. Historiográfica, en tanto que las académicas daban cuenta de los procesos de creación, desarrollo, difusión y estabilización de los temas y géneros poéticos, pero también de la evolución de los gustos literarios del periodo; socioliteraria, porque evidenciaban las aspiraciones personales e intereses de poder propias tanto de sus integrantes como de sus promotores. De ahí que por la innegable luz que el estudio de las academias estudio arroja para una mayor comprensión de la literatura del momento, en particular, y una más completa visión de la evolución de la historia de la literatura hispánica, en general, sigan haciendo falta estudios que den cuenta del alcance de su difusión y recepción.
\end{abstract}

\section{DESCRIPCIÓN DEL MANUSCRITO DE LA BIBLIOTECA NACIONAL DE ESPAÑA}

Resulta, en este sentido, de particular interés la academia literaria consignada en la colección de manuscritos de la Biblioteca Nacional de España bajo la signatura MSS/5651. E1 códice que recoge la singular manifestación poética - de 22 x $16 \mathrm{~cm}$ en un muy buen estado de conservación- presenta una encuadernación en holandesa del siglo XIX que combina tapas de cartón recubiertas de papel con marcas de agua con un lomo de cuero negro en el que, en letras doradas, entre filetes dorados puede leerse: «ACADEMIA | DE | LAXEMBURG». Consta el volumen de 59 folios, con una doble numeración arábiga en la esquina superior derecha. La primera, manuscrita y con tinta de la época, va del 71 al 131, presentando errores de numeración, al saltar los números 98 y 120. De esta primera foliación se desprende la existencia previa de un volumen más extenso del que posteriormente se habría desgajado desgajó la academia. En lo que concierne a la segunda numeración, moderna y a lápiz, coincide estrictamente con el número de folios del volumen en su versión autónoma, yendo la numeración del 1 al 59. El códice así conformado se debe íntegramente a la copia de una misma mano, con escritura de siglo XVII en letra humanista de fácil lectura, con escasas abreviaturas y que destaca por la clara separación entre las palabras, siendo muy poco habituales los signos de puntuación. No hay apenas correcciones, añadiduras o reelaboraciones textuales, salvo la tachadura del nombre de uno de los poetas que participaron en la academia literaria, en el folio 20r. Según reza el breve texto introductorio indirectamente dirigido al lector, la autoría de esta recopilación manuscrita habría recaído en quien fuera el secretario de la academia, llamado Luis de Heredia.

\section{LA LITERATURA CASTELLANA EN LA CORTE IMPERIAL}

La singularidad de la academia consignada en los folios del manuscrito de la Biblioteca Nacional de España reside en su carácter inusual, ya que da cuenta de cierto tipo de actividad

\footnotetext{
${ }^{1}$ Véase Bègue, 2007, 2013 y 2017.
} 
poética en lengua castellana fuera de las la Península. Radica su interés en haber tenido lugar cerca de Viena, capital del Imperio, cuando escasean las noticias que llegan a nuestros días de las manifestaciones literarias españolas, privadas o públicas, que hubieron de darse en tierras de la rama menor de la casa de Habsburgo. Tal y como dejó consignado Heredia en la página de título de sus hojas manuscritas ${ }^{2}$, la academia se celebró en el Real Sitio de Laxenburg el día 23 de mayo de 1672 a petición y en presencia de las majestades cesáreas del Sacro Imperio Romano Germánico, el emperador Leopoldo I y su esposa Margarita Teresa de Austria (Madrid, 12 de julio de 1651-Viena, 12 de marzo de 1673), infanta de España, hija del rey Felipe IV de España y de doña Mariana de Austria, hermana del Emperador y reina gobernadora de la Monarquía hispánica durante la minoría de edad de Carlos II.

Los desposorios de los emperadores, que confirmaban los estrechos vínculos dinásticos existentes entre las dos ramas de la casa de Austria, se habían celebrado por poderes en la corte de Madrid el 25 de abril de 1666, día de Pascua, siendo representante del emperador el duque de Medinaceli, en presencia del niño rey Carlos II y de la regente, su madre, doña Mariana, con asistencia del conde de Pötting, embajador imperial, y de los grandes de la Corte. La emperatriz y su séquito salieron de Madrid el 28 de abril con destino a Denia, puerto desde donde se dirigió a Barcelona el 16 de julio en uno de los buques de la Armada Real de España, escoltada por esta y por las galeras de Malta y las del gran duque de Toscana. La flota llegó a la ciudad condal dos días después, el 18 de julio, siendo recibida con grandes salvas. Una leve indisposición de la emperatriz retrasó la continuación de su viaje hasta el 10 de agosto, fecha en la que la comitiva zarpó para el marquesado de Finale adonde llegó el 20 de agosto. Allí doña Margarita Teresa fue recibida por el gobernador del Estado de Milán, don Luis Guzmán Ponce de León. El 1 de septiembre, la emperatriz salía de Finale con rumbo a la ciudad de Milán, adonde llegó al día siguiente, si bien la entrada triunfal no se hubiera de realizar hasta el día 15. El 24 de septiembre, la comitiva reanudó su jornada dirigiéndose hacia la Serenísima República de Venecia. El 8 de octubre llegaron a Roveredo, localidad del principado episcopal de Trento que había sido elegida para las solemnes entregas, que se llevaron a cabo el 10 de octubre. En nombre del rey de España y de la reina gobernadora, el embajador extraordinario, camarero mayor y jefe de la jornada, don Francisco Fernández de la Cueva y Enríquez de Cabrera, octavo duque de Alburquerque, entregó a la emperatriz Margarita Teresa al príncipe de Dietrichstein y al cardenal Ernesto de Harrach, príncipe-obispo de Trento, enviados cesáreos para la ocasión. Diez días después, el 20 de octubre, la nueva comitiva abandonó Roveredo, atravesando el Tirol, pasando por Carintia y Estiria, y alcanzando el 25 de noviembre Schottwien, situado a doce leguas de Viena, donde fue a buscarla el emperador. La entrada oficial en la capital austriaca tuvo lugar finalmente el 5 de diciembre de 1666, entre festejos y espectáculos.

Con la presencia de la joven emperatriz, que había cumplido los quince años durante su viaje a Viena, se introdujo un cierto aire español en una corte imperial donde la lengua de la cultura imperante era el italiano ${ }^{3}$. Sabemos que Leopoldo I trató de complacer y de festejar a

\footnotetext{
${ }^{2}$ Academia que, de orden de sus Majestades Cesáreas, y en su imperial presencia, se celebró el día 23 de mayo de 1672 en el Real Sitio de Laxemburg, f. 1r.

${ }^{3}$ Tal era la influencia italiana en la capital austriaca, que Umberto De Bin llegó a afirmar que «così vediamo che a Vienna alla Corte degli ultimi Asburgo [l'italiano] ha veramente una casa propria» (De Bin, 1910, pp. 8-9). El estudio de De Bin muestra además de manera magistral el proceso de progresivo afianzamiento de los italianos en Viena, llegando a ocupar éstos posiciones diversas en el servicio imperial -ingenieros de guerra, oficiales militares, cargos palatinos, consejeros políticos, etc. - y a constituir una auténtica «aristocracia áulica» particularmente en la segunda mitad del siglo XVII. Por supuesto, esta situación se confirmó cuando Leonor de Gonzaga (Mantua, 1598-Viena, 1655), hija menor Vicente Gonzaga, duque de Mantua, y Leonor de Médicis, madrastra del futuro Leopoldo I, casó en segundas nupcias con el emperador Fernando III. Llegó entonces a constituir una verdadera corte italiana en Viena. Paralelamente, lo italiano fue considerándose, desde Fernando II, como la máxima expresión del buen gusto, supliendo una lengua alemana artísticamente extranjera para la casa de Austria. Así, pues, las artes de origen italiano ocuparon la corte imperial, estableciéndose en ella verdaderas dinastías de artistas. La música, por ejemplo, se había convertido en una herencia artística para los Habsburgo
} 
su joven esposa, procurando que se representasen comedias y zarzuelas españolas y que se organizasen diversiones y fiestas particularmente para doña Margarita Teresa y los miembros de su casa: una camarera mayor, una señora de honor continua, una señora de honor y guardamayor, tres damas, una azafata, una dueña de retrete, una comadre, el confesor de doña Margarita, un médico, un sangrador, un secretario y varios criados ${ }^{4}$. Y es que, si el emperador podía valerse de diversas lenguas en sus correspondencias - alemán, latín, italiano y español, si bien esta última no con la debida perfección-, no ocurría lo mismo con la infanta de España, que no había llegado a expresarse en más lengua que el castellano, pese a su buen deseo de aprender el alemán, como manifiesta el hecho de que había pedido al conde Franz Eusebius Grafen von Pötting, embajador imperial en Madrid, una gramática alemana antes de emprender su viaje a Viena ${ }^{5}$.

Además, era Leopoldo I muy aficionado a las letras - gran lector, mostraba una pasión por los libros y había formado, junto con su tío el archiduque Leopoldo Guillermo de Habsburgo (1614-1662), y su madrastra Leonor, un cenáculo que se divertía versificando 6 - y a las artes, particularmente al teatro español y, especialmente, al de Calderón de la Barca, cuyas comedias hizo representar en castellano por los criados de la embajada de España en las fiestas con que celebraba siempre el cumpleaños de su hermana la reina Mariana de Austria, el 22 de diciembre de cada año. La pasión del emperador por el arte dramático era tal que solo ocho días después de la muerte de Felipe IV, esto es, durante un periodo de duelo regio, asistió a una ópera en Innsbruck, adonde había ido recibir el pleito homenaje de los Estados del Tirol, diversión que le valió duras críticas en la corte de Madrid ${ }^{7}$.

Leopoldo I mandaba a España ejemplares de las obras teatrales representadas en Viena a su embajador, para que las entregase a doña Mariana de Austria y a Carlos II y las difundiese entre los embajadores en Madrid —dando de este modo a conocer el lujo y magnificencia de las representaciones y espectáculos de la corte austriaca-, mientras pedía que se le remitiesen desde Madrid copias de piezas teatrales españolas ${ }^{8}$, tal como se manifiesta en la correspondencia que mantuvo con el Embajador imperial en Madrid. En la carta que escribió el 6 de enero de 1667 al conde de Pötting, por ejemplo, le pedía al plenipotenciario que le enviase unos tonos humanos que le pedía «constantemente» doña Margarita Teresa, la música de Celos aun del aire matan, comedia de Calderón, así como una copia de una comedia del mismo autor, repitiendo con insistencia la demanda en cinco ocasiones -el 16 de marzo, 31 de marzo, 13 de abril, 11 de mayo y 21 de julio- ${ }^{9}$. Unos meses después, el 31 de marzo, le volvía a pedir tonos humanos, a solo, dos y tres, al mismo tiempo que acusaba recibo de unos villancicos ${ }^{10}$.

Pero quizás donde mejor quede reflejado el gusto por las artes del emperador sea a través del colorido retrato de Jan Thomas realizado para celebrar los desposorios con la infanta

desde Carlos V y, por ser los garantes del ansiado buen gusto, se hicieron imprescindibles los «poetucoli» bajo los dos últimos Habsburgo del siglo XVII. Leopoldo I llegó así a tener, al final de su reinado, casi un centenario de personas a su servicio, entre profesores de orquesta y cantantes (De Bin, 1910, pp. 13-15). Y fue con Leopoldo I, que escribía versos en italiano, estudiaba la historia de los autores italianos y dedicaba un teatro a los melodramas italianos, cuando el italiano se convirtió en lengua áulica y se extendió por toda la corte imperial. Al expresarse en ella, el emperador Leopoldo recordaba con placer que era el jefe del Sacro Imperio Romano (Ibíd., pp. 26-27). Tal era la presencia de la lengua italiana, que llegó a publicarse un periódico en italiano bajo el nombre de Il Coriero ordinario, con una periodicidad de dos números a la semana (Ibíd., p. 30).

${ }^{4}$ Villa-Urrutia, 1905, pp. 87-93.

${ }^{5}$ Ibíd., pp. 14-15.

${ }^{6}$ De Bin, 1910, p. 25.

${ }^{7}$ Villa-Urrutia, 1905, p. 50.

${ }^{8}$ Varey y Shergold, 1970, p. cvii.

${ }^{9}$ Ibíd., p. cviii.

${ }^{10}$ Véase Varey y Shergold, 1970, pp. cv-cviii, donde quedan repertoriados los envíos del Emperador y donde están transcritas las cartas, redactadas en alemán. 
española. El cuadro conocido como El emperador Leopoldo I con traje de teatro representa al monarca disfrazado de Acis, para la comedia La Galatea (1667) y se completa con otro de la emperatriz Margarita pintado para la misma ocasión.

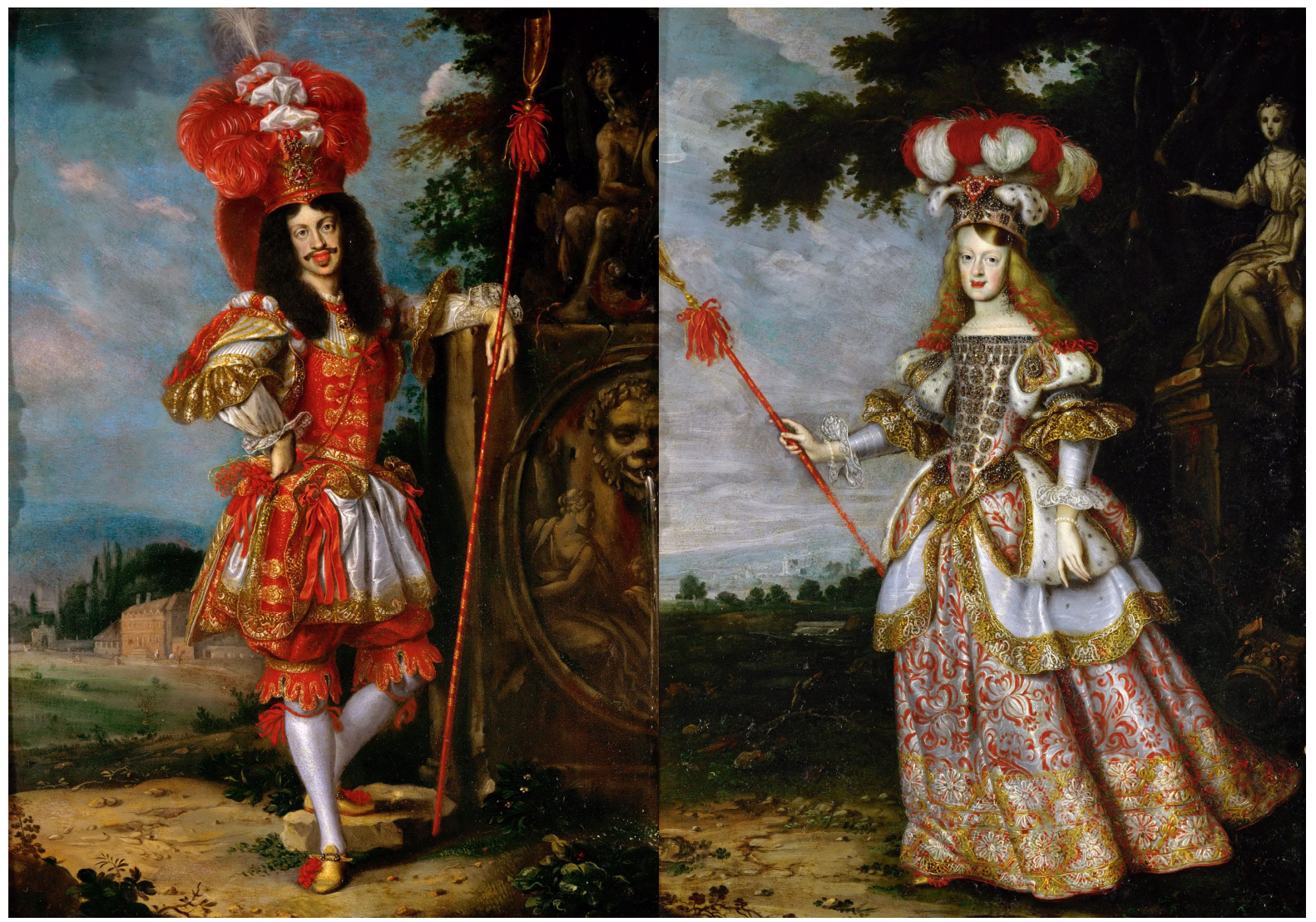

Jan Thomas (1617-1678), El emperador Leopoldo I con traje de teatro (1667) y La infanta Margarita Teresa, emperatriz, con traje de teatro (1667) (Viena, Kunsthistorisches Museum)

La temática de ambos retratos viene a recordar el gusto del emperador por la literatura en general y particularmente por las artes escénicas, convirtiéndose la corte imperial, además, con la llegada de la infanta Margarita Teresa, en centro de interpretación y representación de piezas españolas, en alternancia con las obras italianas que seguirían ejerciendo un claro predominio en los escenarios palaciegos ${ }^{11}$.

En este contexto, el 25 de abril de 1667 se estrenaba en Viena, en celebración del primer aniversario del desposorio imperial, la comedia Las vitorias del amor contra el desdén en el más amado y aborrecido, "cuyo final se [había modificado] con la adición de un torneo que pone brillante fin a la fiesta; una loa cortesana, que la abre; un romance cantado a la Emperatriz, que sigue a la loa; y dos entremeses - El plenipapelier y Las beatas - cuyos finales se [modificaron] también mediante añadidos» ${ }^{12}$. Siendo el autor del primer entremés Francisco de Avellaneda, y del segundo, Antonio Barrientos ${ }^{13}$.

$\mathrm{Al}$ año siguiente, hubo representación de una «comedia española con música y tramoyas La flecha del amor», de autor desconocido. El mismo año de 1668, con motivo del cumpleaños de la reina gobernadora de España, doña Mariana de Austria, madre de la emperatriz y hermana

\footnotetext{
${ }^{11}$ Según el catálogo de Weilen, de las 66 obras representadas en los teatros palaciegos a las que pudo asistir la emperatriz Margarita Teresa, solo cinco eran en español, siendo las demás italianas (1901, pp. 11-19).

${ }^{12}$ Reyes Peñas, 1995, p. 195. Weilen consigna únicamente la loa en su catálogo (Weilen, 1901, p. 12, nº 76). Véase asimismo Villa-Urrutia, 1905, p. 48.

${ }^{13}$ Reyes Peñas, 1995, pp. 202-203.
} 
del Emperador, los criados del embajador español, conde de Castellar llevaron al escenario el 22 de diciembre la comedia Darlo todo y no dar nada, de Calderón ${ }^{14}$, que el mismo Leopoldo describía como «comedia española, y por esto ya es mejor de todas las otras fiestas» ${ }^{15}$.

Y con el mismo motivo se representó en el salón del palacio imperial de Viena, en el año 1669, Aun vencido vence amor o el Prometeo, atribuido a un tal Ximenes, con música del compositor y libretista italiano Antonio Draghi (Rímini, 1634-Viena, 1700).

El 1 de mayo de 1671, el embajador español organizaba en el parque del palacio de Laxenburg la representación de la comedia titulada Del mal lo menos ${ }^{16}$, de Antonio Folch de Cardona, marqués de Castelnou, con su loa y dos entremeses. Fue así, pues, cómo el palacio de Laxenburg, situado a unos $30 \mathrm{~km}$ de Viena, y, junto con el de Schönbrunn, la residencia de verano más importante de los Habsburgo, se convirtió en uno de los escenarios de los recreos literarios españoles organizados para la emperatriz. Quizá haya influido en la elección de la obra el hecho de que la camarera mayor de la emperatriz fuera doña Margarita Teresa de Eril y Mayno (1629-1679), tercera condesa de Eril, viuda de don Alfonso Folch de Cardona y Borja, primer marqués de Castelnou, y madrastra del mencionado don Antonio, quien la había acompañado hasta Italia en su calidad de capitán de corazas del Rey ${ }^{17}$. El 22 de diciembre se estrenaba, en celebración del cumpleaños de la reina gobernadora doña Mariana de Austria, la comedia Fineza contra fineza, de Calderón de la Barca, a la que acompañaron dos entremeses ${ }^{18}$, Orfeo y Eurídice y La novia barbuda, ambos con música compuesta por el mismo Leopoldo I.

Según Weilen, el 8 de junio de 1672, se estrenó una «comedia en habla española» — «Comödie in spanischer Sprache»— ${ }^{19}$. Y con motivo del cumpleaños de doña Mariana de Austria, el emperador elegía la representación de la zarzuela La flecha de amor, de autor desconocido y cuyo texto fue impreso por Jean Bautista Hacque ${ }^{20}$.

Por último, el 18 de enero de 1673, entre las festividades organizados en celebración del cumpleaños de la archiduquesa María Antonia, figuraba la representación de una comedia de Agustín Moreto, Primero es la honra, con música de Draghi ${ }^{21}$.

Si bien no cesó el interés de los austriacos por las obras teatrales españolas ${ }^{22}$, la muerte de la emperatriz Margarita Teresa, acaecida el 12 de marzo de 1673, a los 21 años de edad, significó el cese de las representaciones en lengua castellana en los escenarios de la corte de Viena $^{23}$.

Así, pues, la celebración de la academia del 23 de mayo de 1672 se enmarcaba en el movimiento cultural vienés de inflexión hispánica que encontró su origen en la presencia de la hermana de Carlos II en la corte imperial. No era, con todo, esta la primera vez que el palacio de Laxenburg, propiedad de la familia Habsburgo desde 1333, había sido el teatro de distracciones destinadas a amenizar la vida austriaca de la emperatriz española. Si bien hasta la

\footnotetext{
${ }^{14}$ Weilen, 1901, p. $13, \mathrm{n}^{\mathrm{o}} 82$.

${ }^{15}$ Citado en Villa-Urrutia, 1905, p. 48 y Varey y Shergold, 1970, p. cvi.

${ }^{16}$ Weilen, 1901, p. 16, no 104.

${ }^{17}$ Villa-Urrutia, 1905, p. 88.

${ }^{18}$ Reyes Peña, 1997, p. 119. Villa-Urrutia señaló que la comedia de Calderón probablemente fuese El postrer duelo de España, «para la que mandó componer Leopoldo "«entremeses en música”» (Villa-Urrutia, 1905, p. 88).

${ }^{19}$ Weilen, 1901, p. 16, no 107.

${ }^{20}$ Ibíd., p. 16, no 108. Véase también Villa-Urrutia, 1905, p. 49, y Reyes Peña, 1997, p. 119.

${ }^{21}$ Villa-Urrutia, 1905, p. 49.

${ }^{22}$ Véase Varey y Shergold, 1970, p. cviii, donde quedan manifiestan la afición de Ferdinand Bonaventura (16371706), conde de Harrach, que anotaba cuidadosamente las obras a cuya representación había asistido en los teatros palaciegos y comerciales durante su segunda estancia en Madrid (1673-1676), y la pasión de su hija, María Josepha, futura condesa de Kuenberg, que llevó consigo a Viena una colección de obras teatrales impresas.

${ }^{23}$ Por supuesto, cabría añadir a las obras representadas en español las no pocas piezas interpretadas en italiano, algunas de ellas traducidas de obras españolas, como fue el caso, por ejemplo, de la obra Benche vinto vince amor u il Prometeo. Opera in musica, tradotta dall' Spagnuolo, estrenada el 22 de diciembre de 1669 con motivo del cumpleaños de Mariana de Austria (Weilen, 1901, p. 14, nº 87).
} 
actualidad no nos había llegado noticia alguna de la organización de academias literarias «a la española» ${ }^{24}$ fuera de los territorios de la Monarquía de España ${ }^{25}$ y de ahí el singular interés de esta Academia de Laxemburg, que pasamos a estudiar en las páginas que siguen.

\section{Un CONTEXTO EUROPEO BÉLICO: LOS INICIOS DE LA GUERRA DE HOLANDA}

El carácter singular de nuestra manifestación literaria radica asimismo en el contexto histórico en el que se desarrolló. En efecto, la academia se celebraba en los momentos iniciales de la Guerra de Holanda, que vio oponerse, en un primer tiempo, al reino de Francia y las Provincias Unidas. Estas habían desempeñado un papel crucial en la resolución de la reciente Guerra de Devolución emprendida por Luis XIV en 1667 fundándose esencialmente en el «derecho de devolución», una antigua costumbre del ducado de Brabante, estado de la circunscripción de Borgoña, una de las diez circunscripciones del Círculo Imperial, costumbre según la cual los hijos de un primer matrimonio —en este caso, María Teresa, esposa de Luis $\mathrm{XIV}$ - eran los únicos herederos de sus padres, en detrimento de los hijos nacidos de un segundo matrimonio - en este caso, Carlos II de España- ${ }^{26}$. Como freno a las pretensiones galas se había constituido la Triple Alianza formada por Inglaterra, las Provincias Unidas y Suecia.

La coalición de las máximas potencias navales, Inglaterra y Holanda, jugó un papel decisivo en la política internacional del resto del siglo XVII, y se convirtió en el principal obstáculo para la agresiva política expansionista de Luis XIV. Aunque la alianza nunca llegaría a combatir con armas al reino de Francia, su misma formación supuso, sin embargo, una amenaza suficiente para que el Rey Cristianísimo detuviera su ataque y firmara con España el Tratado de Aquisgrán el 2 de mayo de 1668, poniéndose así fin a la Guerra de Devolución. El golpe había sido duro para Luis XIV, ya que sus relaciones siempre habían sido amistosas con los tres países.

El soberano francés, ansioso de hacerse con los últimos territorios españoles colindantes con la frontera francesa - Países Bajos españoles y Franco Condado-, se había percatado de que debía eliminar a las Provincias Unidas si quería llevar a buen puerto sus pretensiones. Además, la Triple Alianza había demostrado que las Provincias Unidas eran la única nación con valor suficiente para resistir los afanes expansionistas de Francia. La guerra de Holanda surgía así de las ambiciones de Luis XIV de aniquilar a la potencia holandesa para extender su reino en Flandes, eliminando a un tiempo a un más que temido adversario comercial. Par ello, el rey de Francia decidió socavar la influencia holandesa y acabar con su poderío comercial, dando así lugar a una ofensiva diplomática para desvincular de la alianza a Inglaterra, que así lo hizo el 1 de junio de 1670 por el Tratado de Douvres - a cambio de tres millones de libras y la promesa de puertos holandeses-, y a Suecia, que lo abandonaría en abril de 1672, comprometiéndose el rey Carlos XI de Suecia a atacar a los príncipes protestantes si estos acudieran en socorro de las Provincias Unidas.

\footnotetext{
${ }^{24}$ Así lo precisa el fiscal de la academia en su vejamen (f. 43v), aunque la reunión literaria pudo contar, como veremos, con algunas composiciones en italiano.

${ }^{25}$ Sí tenemos constancia, en cambio, de la existencia de tres academias italianas en Viena: la Accademia dei Crescenti del archiduque Leopoldo Guillermo y del emperador Fernando III, fundada en 1657; la Accademia degli Illustrati, fundada por la emperatriz viuda Leonor de Gonzaga en 1667 y que duraría hasta por lo menos 1677; y la fundada por el emperador Leopoldo I en 1674 y de cuyas sesiones no se tienen noticias después de 1676 (De Bin, 1910, pp. 45-70). En esta última, el procedimiento habitual era más o menos el siguiente: primero, los académicos oficiales leían ante el auditorio, casi siempre según un orden establecido, sendos discursos sobre un tema preestablecido. Seguía a continuación, después de los discursos, un intermezzo de canto y música, por músicos profesionales y relacionado al tema propuesto, y cerraba la sesión la recitación de poemas mandados para ser leídos por poetas no académicos (Ibíd., pp. 57-58).

${ }^{26}$ Gresset, Gresser, Debard, 1988, p. 171.
} 
Paralelamente, Luis XIV, temeroso de la imprevisible actitud de los príncipes alemanes y del Emperador, dedicó todo el año de 1671 a una intensa actividad diplomática destinada a establecer una alianza con las potencias germánicas y el Imperio o cuanto menos, a asegurarse su neutralidad. Después de recibir el apoyo de Maximiliano de Baviera, príncipe-elector de Colonia, el monarca francés consiguió obtener la neutralidad de Leopoldo I el 1 de noviembre de 1671. El Emperador germánico aceptaba no intervenir en el futuro conflicto, a condición de que este se desarrollara fuera de los territorios alemanes.

Conformada su red de alianzas, y con un ejército de más de 120.000 soldados bien armado y preparado, el 6 de abril de 1672, Francia declaraba la guerra a las Provincias Unidas, después de que lo hubiese hecho Carlos II de Inglaterra el 28 de marzo de 1672, obligando a los Países Bajos españoles a entrar en la contienda, en virtud de un pacto defensivo que había firmado con los holandeses en febrero de 1672.

Los franceses iban a invadir rápidamente las Provincias Unidas, llegando para ello a cruzar el Rin. Sería entonces cuando el Emperador resolvería romper con la promesa de neutralidad hecha a Luis XIV, aliándose el 23 de junio con Federico Guillermo I, príncipeelector de Brandeburgo y el 25 de julio con las Provincias Unidas. Más de un año después, se constituiría, el 30 de agosto de 1673, la Gran Alianza de La Haya entre las Provincias Unidas, España, Austria, el Palatinado y el ducado de Lorena.

\section{ANÁLISIS DE LA ACADEMIA LITERARIA VIENESA DEL 23 DE MAYO DE 1672}

Durante el periodo inicial de neutralidad de Leopoldo I en la guerra franco-holandesa se habría celebrado, pues, el día 23 de mayo de 1672 - esto es, poco más de un mes después del inicio de la contienda y exactamente un mes antes de la intervención del Emperador- una academia literaria en lengua española, que intercala cuatro composiciones en italiano, en el palacio de Laxenburg, real sitio de verano, a petición y en presencia de las majestades cesáreas, deseosas de asistir a un tipo de actividad poética que conoció una gran fortuna en el siglo XVII.

La organización interna de la academia, que tuvo lugar en la corte de Viena «más por obedecer que por lucir» (f. 1v), según el secretario, observó la estructura propia de la mayor parte de las academias literarias ocasionales celebradas en los distintos territorios de la Monarquía hispánica: después de los textos preliminares formados por una introducción (ff. 2rv), la oración del presidente (ff. 3r-6v) y las cedulillas preparadas por el secretario (ff. 7r-15v), se sucedieron a continuación los distintos asuntos tratados por los poetas convocados para la ocasión (ff. $17 \mathrm{r}-39 \mathrm{v})$, concluyendo la academia literaria con un vejamen, texto del que era autor el fiscal del encuentro poético (ff. 40r-59r).

La introducción de la academia es una letrilla. Ofrece una estructura bipartita constituida de un estribillo polimétrico en el que intervienen un coro de música y una voz y de tres coplas en la que el coro va ritmando el texto de una voz poética por medio de un estribillo. Su propósito es convocar a los poetas que intervendrán en la academia para que acudan a ella en celebración de la emperatriz — «de las aves la reina»- y gocen del amparo y del «influjo divino» del emperador, como queda manifiesto en el estribillo inicial:

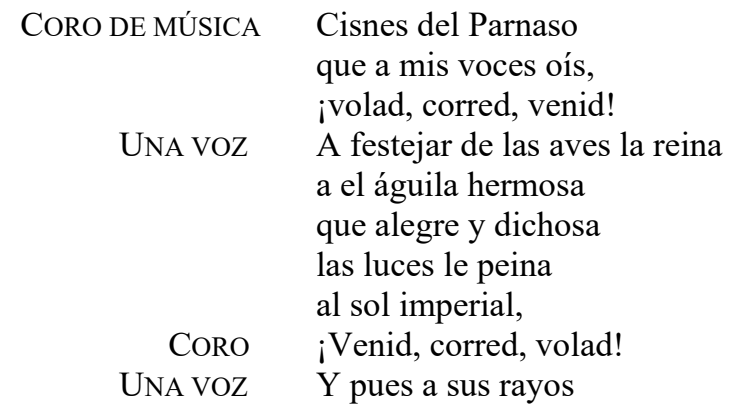




$\begin{aligned} & \begin{aligned} \text { abriles y mayos } \\ \text { dan el parabién... }\end{aligned} \\ \text { CORO } & \text { ¡Volad, venid, corred! } \\ \text { UNA VOZ } & \ldots \text { gozaréis del influjo divino } \\ & \begin{array}{l}\text { que al mundo previno } \\ \text { su imperio feliz. }\end{array} \\ \text { CORO } & \text { ¡Corred, volad, venid! } \\ & \text { (f. } 2 \text { r) }\end{aligned}$

A continuación, las coplas ponen en evidencia los dos idiomas español e italiano en las que serán recitados las composiciones poéticas correspondientes a los asuntos, insistiendo en el carácter musical y festivo del evento mediante una referencia a las Musas - «entre la Euterpe italiana / y la española Talía» (f. 2r) - Subrayan asimismo la protección imperial de la que gozarán los poetas en Laxenburg — «Águila imperial» (f. 2v) - y el amparo del dios Apolo que, con motivo de la academia, convirtió al Danubio en nueva fuente de inspiración.

Aunque la autoría de la introducción no queda especificada en el manuscrito, sabemos que el texto solía encargarse al secretario de la academia literaria ${ }^{27}$, por lo que habría sido su autor Luis de Heredia, de quien no hemos podido localizar ningún otro dato bio-bibliográfico, más allá de su participación en la academia que nos ocupa.

La oración de la academia, cuya composición le correspondió a don José de Villarroel, por ser el presidente del evento, está formada por un largo romance octosilábico en el que se inserta una octava real y que remata por otras tres octavas reales. Como era costumbre en las oraciones académicas de la segunda mitad del siglo XVII ${ }^{28}$, en ella queda patente la presencia de la elementos musicales, manifestada por la intercalación, a intervalos regulares, de cinco coplas de romance cantadas y el uso de instrumentos, indicado por medio de didascalias — «Suena un clarín» (f. 5v) - . Con este poema preliminar, el presidente de la academia quiere presentar, por medio de un clásico filtro poético y ficcional, las circunstancias que originaron y justificaron la organización del evento.

En su caso, Villarroel narra cómo, siguiendo un gamo al que estaba cazando, penetró en lo más profundo de una lúgubre y «cóncava gruta» (f. 3r). Allí descubrió un «mendigo extranjero rayo» (f. $3 \mathrm{v}$ ) al que decidió seguir avanzando penosamente por entre una naturaleza hostil hasta que, cuando se proponía a apagar su sed en un arroyo, oyó la voz de una ninfa que le avisaba del peligro que corría bebiendo las aguas del mismo. Ante las inquietudes del presidente, la ninfa acabó indicándole que

$\begin{aligned} \text { Canta la voz } & \\ & \text { Reliquia es del Parnaso } \\ & \text { que corre a que le gusten } \\ & \text { para un sagrado empeño } \\ & \text { el español y el italiano numen. } \\ & \text { (f. } 4 \mathrm{v})\end{aligned}$

Villarroel comprendió entonces que había alcanzado el Pindo, cuyas dos cimas así como la voluntad imperial - «el ave de dos cuellos»- justificaban el empleo de las dos lenguas española e italiana, situación que no había dejado de causarle sorpresa:

Pero ¿qué empeño sagrado

manda que se mancomunen plumas de Italia y de España? ¿A que una cítara pulsen?

\footnotetext{
${ }^{27}$ Bègue, 2007, p. 26.

28 Ibíd.
} 
Obediente, el presidente de la academia estuvo a punto de beber de la fuente Aganipe, cuando apareció un águila de oro y piedras preciosas portando en sus garras un mensaje en el que se anunciaba, entre clarines, la celebración de la reunión poética:

\begin{abstract}
Una academia Laxemburg mantiene, que a la copia del sol pompa romana con obsequiosa adoración previene, dando a culto divino gloria humana. La fama atenta publicando viene que la española musa o la toscana que del Danubio bebe cristal sacro venga a cantar del sol al simulacro. (f. $5 \mathrm{v})$
\end{abstract}

Tras esta aparición, Villarroel se apresuró a alcanzar Laxenburg, donde se encontraba «el concurso más ilustre / de cisnes que a la Helicona / la beben sin que la enturbien» (f. 6r), y que lo admiten en su academia ofreciéndole la silla de presidente. La oración concluye finalmente con tres octavas reales que convocan a los poetas, invitándolos a que celebren a la emperatriz.

En lo que concierne al conjunto conformado por las cedulillas y su introducción previa, fue obra del secretario de la academia, Luis de Heredia. Si las primeras se presentan bajo la forma tradicional de una sucesión de textos en prosa que concluyen con una composición poética breve -en nuestro caso, cinco quintillas y una redondilla-, la introducción ofrece una composición bipartita: un primer poema fue elaborado a partir de endecasílabos y heptasílabos organizados en pareados, siendo el segundo, titulado "Carta de Apolo», un romance octosilábico. Escritos en estilo jocoserio, el propósito de ambos textos es eminentemente festivo. Así, por ejemplo, la introducción relata en tono burlesco, por medio de la ficción, el empeño del secretario por convertirse en poeta, que procura para ello alcanzar el monte Parnaso. Recibió entonces una carta del dios Apolo que, informándole de que había sido elegido secretario para la celebración de la academia que estaba a punto de reunirse en la corte de Viena, se veía en la obligación de hacerle poeta, por lo que, en su ayuda, despachaba Pegaso con «ocho arrobas de romances y una azumbre de sonetos» (f. 9v). Adjuntaba asimismo Apolo a su escrito las seis cedulillas con las que el secretario pudo acudir a la academia.

En cuanto a los asuntos, fueron presentados en dos tiempos, siguiendo sendos procedimientos. El primero, que corresponde a las ocho primeras intervenciones poéticas, hizo alternarse las composiciones italianas con las españolas (ff. 17r-31r). Siguiendo el orden de los asuntos así preestablecido, y tales como quedaron consignados en el manuscrito, sus autores fueron Nicolás Minate, Juan Marín, Francisco Tintoribus, José de Villarroel el Mozo, Gilberto Ferri, Cristóbal Pertusato, Gerónimo Branchi e Isidro de Ángulo y Velasco respectivamente.

Entre ellos, puede destacarse una primera categoría de participantes formada por hombres de letras que pusieron su pluma al servicio de las majestades imperiales.

A este grupo perteneció Nicolò Minato (Bergamo, ca. 1627-Viena, 1698), autor del primer asunto con un poema compuesto en octavas reales y en lengua italiana - titulado «Un aghirone che per fuggire dalli falconi si ricoriera a piedi di S.M.» (ff. 17r-v)—. Fue Minato un profuso y reconocido libretista. Había llegado a la corte del emperador Leopoldo I en 1669, después de una etapa veneciana de casi veinte años (1650-1669) en la que escribió once libretti, 
la mayor parte para el compositor Francesco Cavalli. Si bien había empezado a escribir para este último en 1650, no sería hasta los años 1660 cuando abandonaría su profesión de abogado para dedicarse plenamente a la escritura y a la empresa teatral. Antes de partir para la corte imperial, en la que acabaría sus días, había sido miembro de diversas academias literarias, entre las cuales figuraban la Accademia degli Imperfetti, cuyos miembros se dedicaban al estudio de la jurisprudencia contemporánea y clásica. En Viena produjo más de 170 libretti, tanto para la ópera seria como para fiestas teatrales, y escribió abundantemente para espectáculos ocasionales organizados con motivo de cumpleaños de miembros de la familia real o fiestas y bodas. Asimismo, formaría parte de la academia literaria que mantendría el emperador Leopoldo I de 1674 a 1676, junto a Filippo Sbarra, hijo del poeta cortesano Francesco Sbarra, Carlo Domenico Draghi (1669-1711), hijo del maestro de capilla Antonio Draghi, o Cristoforo Pertusati, participante, como él, en esta academia del 23 de mayo de $1672^{29}$.

De la misma manera, Gilberto Ferri, a quien correspondió el quinto asunto, lo que lo llevó a componer para la ocasión la cantata italiana titulada «Che la ruggiada è pianto del Aurora» (ff. 25r-v), puede incluirse en este primer grupo de poetas. Era a la sazón secretario de don Wenzel Eusebius von Lobkowitz (1609-1677), segundo príncipe de Lobkowitz ${ }^{30}$. Este llegó a ser consejero de los emperadores Fernando III y Leopoldo I en la corte austriaca, como presidente del Gabinete de Guerra (desde 1652) y del Consejo Privado (desde 1669). Al estar además el príncipe en relación muy cercana con la emperatriz Margarita Teresa, no es de extrañar que Ferri pusiera su pluma al servicio de las majestades cesáreas. Escribió dos libretti para oratorios del compositor Antonio Draghi, cantados en Viena: Li sette dolori di Maria Vergine (1670) e Il limbo aperto (1672). Diversas composiciones poéticas suyas - cantatas, madrigales y odas-, algunas de ellas escritas en 1672, fueron recogidas en un manuscrito conservado bajo el rótulo de Poesie di diversi a [utori e ar]gumen[ti] en la Biblioteca Nazionale Centrale Vittorio Emanuele II de Roma, en los folios 73r-82 $\mathrm{r}^{31}$.

Entre los literatos de la academia figuraba también Girolamo Branchi, que respondió al asunto siete con la composición italiana titulada «A una dama, che leggendo un viglietto dell'amante le fu da una farfalla estinto il lume» (ff. 28r-v). Desempeñaba en la corte el cargo de historiador del emperador Leopoldo I. Como tal, escribió Dell'historia austriaca (Viena, Johann Peter van Ghelen, 1688-1691, 2 vols.), aunque también dedicó su pluma a la escritura poética, las más veces ocasional y de elogio, como atestiguan las tres odas siguientes: Nelle felicissime nozze delli serenissimi signori Ferdinando Carlo, duca di Mantova, Monferrato, etc., et Anna Isabella, principessa di Guastalla, ode di Girolamo Branchi (Viena, Johann Baptist Hacque, 1671), Nell' Occasione della partenza al commando delle truppe di Sua Maestà Cesarea nell'imperio, dell'illustrissimo e eccelentissimo signore, il signore Raimondo conte Montecuculli... si toccano le passate imprese di Sua Eccellenza, e si presagisce felicità nelle future. Ode di Girolamo Branchi ([s.1.], [s.n.], 1672) y Nelle... nozze... di Massimigliano

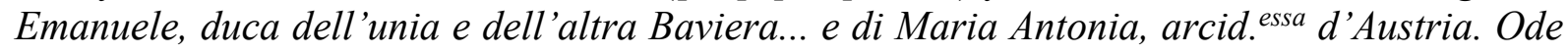
epitalomica (Viena, Herederos de Viviani, 1685). También había sido anteriormente miembro de la Accademia degli Illustrati, fundada por la emperatriz viuda Leonor de Gonzaga ${ }^{32}$.

Otra categoría de escritores fue la formada por los nobles amateurs, nobles para quienes la práctica literaria ponía de manifiesto su condición de gentilhombres-humanistas, de perfectos cortesanos.

Como noble de corte de Leopoldo I vivía en Viena don Cristoforo Pertusati, a quien había correspondido el sexto asunto — «Cuál sea más acertado? ¿El servir un galán pequeño a

\footnotetext{
${ }^{29}$ De Bin, 1910, p. 58; Ritter, 1999, p. 47.

${ }^{30}$ Torsellini, Ristretto dell'Historie del mondo, V, p. 64.

${ }^{31}$ En el margen superior externo del folio $75 v$, puede leerse, por ejemplo: «1672 Madrigali del S. G. Ferri per le Ceneri».

${ }^{32}$ De Bin, 1910, p. 52.
} 
una dama grande o al contrario?»— con un soneto en lengua española (f. 27r). Escribió asimismo la «Respuesta de dama pequeña que desea ser servida de galán grande. Por los mismos consonantes», con otro soneto español (f. $27 \mathrm{v}$ ). Según ciertos testimonios de la época, destacaba Pertusati por su destreza política ${ }^{33}$. Como él, sus hermanos estuvieron al servicio de la casa de Austria. Su hermano Nicola, por ejemplo, pertenecía a la corte de Carlos II, rey de España, como demuestra la amistosa correspondencia que mantenía con la reina madre y gobernadora doña Mariana de Austria, quien lo recordaría en su testamento, dejándole una gema preciosa. Otro hermano suyo, Luca, llegó a ser senador y regente del Consejo Supremo de Italia y fue nombrado presidente del magistrado ordinario y del senado de Milán, cargo que cubrió durante treinta años con total rectitud y sabiduría. Carlos II le concedió el título de conde del Castelferro, situado en el territorio de Alejandría. Como señalamos, don Cristoforo iba a pertenecer, más tarde, a la academia literaria que el emperador Leopoldo I constituyó entre 1674 y 1676 y que se caracterizó por la fuerte representación de los miembros de origen italiano. Fue el encargado de reunir las actas del cenáculo ${ }^{34}$.

Por su parte, José de Angulo, caballero de la orden de Santiago, fue el autor de la glosa correspondiente al octavo asunto, que consistió en describir «¿Cuál sea en un amante más generosa acción? ¿Publicar o callar su amor al no quererle saber su dama?» (ff. 30r-31r). Sin duda alguna, había de tratarse del hijo de don Isidro de Ángulo y Velasco, fiscal de la academia, a quien acompañó a Viena cuando su padre fue designado secretario de la emperatriz doña Margarita Teresa. Así, pues, al residir en la corte imperial, don José de Angulo seguía una tradición familiar, pues su abuelo paterno, Francisco de Ángulo y Velasco, había sido antes tesorero y guardajoyas de la emperatriz María ${ }^{35}$.

Podríamos incluir en el grupo de poetas aficionados a José de Villarroel «el Mozo», a quien tocó escribir en quintillas el cuarto asunto, dedicado «A un galán muy blanco y rubio enamorado de una dama muy negra» (ff. 23r-24v). Puede deducirse de su apodo que hubo de ser el hijo del presidente de la academia. Tenemos también constancia de la atribución a un autor homónimo de una relación de la etapa de la jornada que efectuó doña Margarita Teresa desde Madrid hasta Viena correspondiente al paso por la península italiana, desde su desembarco en el Finale el 20 de agosto de 1666 hasta su entrega al embajador de Venecia ${ }^{36}$. Debió de ser este escrito obra de don José de Villarroel padre.

Pocos datos tenemos sin embargo acerca de Francesco de Tintoribus, que escribió en italiano el poema correspondiente al asunto tercero bajo el título «Bruta dama che adogn'hora si vagleggia alle spechio» (ff. 21r-22r). Aparece mencionado como dedicatario en La valige smarrita (Venecia, 1666), del escritor italiano Antonio Lupis (Molfetta, 1620-Bergamo, 1700). Y ninguna información hemos podido encontrar sobre Juan Marín, autor de las seguidillas de asunto segundo que estaba dedicado «A una novia que la noche de la boda, viendo que el novio, al desnudarse, se quitaba la cabellera, ella se quitó unos dientes postizos que traía» (ff. 19r$20 \mathrm{v})$.

Por lo que al segundo movimiento respecta (ff. 32r-39v), consistió en una sucesión de cinco asuntos, los tres primeros introducidos por una redondilla. Según reza el texto manuscrito, estos asuntos le fueron entregados al secretario de la academia en un pliego cerrado que llevaba la siguiente inscripción: «A la madre academia que se celebra en Laxemburg el día 23 de mayo 1672, en mano de don Luis de Heredia, su secretario» (f. 32r).

\footnotetext{
${ }^{33}$ Tettoni y Saladini, 1841-1847, vol. 5, «Pertusati»: «Politica dexteritate conspicuus».

${ }^{34}$ De Bin, 1910, p. 58; Ritter, 1999, p. 47.

${ }^{35}$ Álvarez de Baena, Hijos de Madrid, t. 2, pp. 429-430.

${ }^{36}$ José Villarroel, Relacion diaria de la iornada de la señora Emperatriz, desde que desembarcò en el Final, hasta que saliò de Lombardia , al ilustrissimo Señor Conde Bartholome Ares..., Milán, Marco Antonio Pandulfo Malatesta, [1667?]. La fecha de publicación está sacada de la dedicatoria, fechada en Milán, el 15 de abril de 1667.
} 
Los asuntos y las correspondientes composiciones poéticas de esta segunda serie fueron los que siguen:

1. «A una señora viuda tan fina con su difunto esposo que, pasando de una provincia a otra, llevó siempre consigo la caja en que iban depositadas sus cenizas. Soneto» (ff. $32 \mathrm{r}-\mathrm{v})$;

2. «A una dama muy esquiva persuadiéndola a que deje de hacerlo. Romance» (ff. 32v$34 \mathrm{r})$

3. «A una dama en títulos de señores. [Seguidillas]» (ff. 34r-35v);

4. «Enano enamorado de mujeres grandes. Canción» (ff. 36r-37r);

5. «Retrato tan de pie quebrado que no ha podido llegar antes a la academia» (ff. $38 \mathrm{r}$ $39 \mathrm{v})$.

Así, pues, los asuntos que se propusieron presentaron una tipología propia de las academias, justas y certámenes poéticos. Los asuntos primero, segundo, tercero, cuarto, quinto y séptimo del primer movimiento, así como los asuntos del segundo presentaron la configuración convencional del asunto por explicar, confiriendo de este modo al poeta una gran libertad que le permitía lucirse. Por su parte, los asuntos sexto y octavo plantearon casos que resolver, teniendo que defender los poetas cada una de las dos premisas que se le ofrecieron y exponiendo las razones que consideraba más convincentes para defender su tesis, procedimiento que confirió a sus composiciones poéticas tintes argumentativos.

Finalmente, la academia concluyó con el convencional vejamen, texto festivo y satírico en el que el fiscal solía criticar, en tono burlesco y jocoserio, las composiciones de cada participante, si bien las más de las veces la burla se centraba en algunas características físicas o morales de los académicos, y en este sentido la reunión de Laxenburg no fue una excepción.

El autor del vejamen y fiscal de la academia, como queda explícitamente señalado en dos ocasiones (ff. 41r y 57v), fue don Isidro de Ángulo y Velasco (1623-1685), padre de don José de Angulo, uno de los poetas académicos. Había sido veedor y proveedor del real sitio de Aranjuez desde el 1 de febrero de 1660 hasta 1666, año en el que el rey Carlos II le mandó pasar a la corte de Viena con el cargo de secretario de doña Margarita Teresa, infanta de España y emperatriz. No era la primera vez que se dedicaba a la escritura poética. En tanto secretario de la Real Congregación del Santo Cristo de San Ginés, don Ignacio había publicado los Triunfos festivos que al crucificado redemptor del mundo erigió la Real Congregación del Santo Christo de San Ginés desta Coronada Villa de Madrid, en la Colocación a su nueva Capilla de su Santa Imagen; antiguo, venerado, y milagroso Simulacro desta Corte. Dedícalos en su nombre a su dignísimo perfecto el excelentísimo señor don Gaspar de Bracamonte y Guzmán (Madrid, Gregorio Rodríguez, 1656) ${ }^{37}$, en los que fueron incluidas varias obras suyas: los romances «Ya no creo que otra vez / en esta iglesia me oirán...» (pp. 28-29), «Por la cruz, capilla y fiestas, / por la procesión y el carro...» (pp. 144-145) y «Escribiros una carta. / Rey crucificado, es fuerza...» (pp. 191-193), las quintillas «A esta fiesta sin querer...» (pp. 58-60) y «Aunque esta congregación...» (pp. 149-151), así como el romance con estribillo «Que al abismo estos triunfos / le miren sentir» (pp. 188-189). Un año antes, había escrito y llevado a la imprenta el poema épico inmaculista titulado Pruebas de la Inmaculada nobleza de Maria Santísima Madre de Dios. Desde el primer instante de su purísima Concepción. Hechas para el Rey nuestro Señor Don Felipe Quarto el Grande (Valencia, Juan Lorenzo Cabrera, 1655). Entre las numerosas composiciones preliminares laudatorias dedicadas al autor, figuraba un texto de su hermano, Esteban de Ángulo y Velasco, caballero de la orden de Santiago y teniente de maestre de campo del Rey en el ejército de Lombardía. La práctica versificadora parecía ser, pues, un asunto de familia.

\footnotetext{
${ }^{37}$ Para un estudio de los Triunfos festivos, véase Hathaway, 1997, p. 219.
} 
El vejamen que escribió don Isidro de Angulo y Velasco para la academia de Laxenburg ofrece una estructura habitual: después de un texto introductorio en prosa, se suceden once cuadros burlescos formados por un texto en prosa rematado con una estrofa métrica breve -una copla de romance (6), una quintilla (2), una redondilla (1), una seguidilla (1) o un romance de pie quebrado (1) - . De igual modo convencional es el recurso de presentar el texto como fruto de una producción onírica o, cuanto menos, fantástica. Así, pues, después de manifestar de manera hiperbólica - y a modo de captatio benevolentiae - su incapacidad para vejar a los poetas que participaron en la academia, para poder llevar a cabo su cometido el fiscal de la misma solicita la ayuda «de aquel oráculo español, Marcial de nuestros siglos, Séneca de nuestras edades, Cicerón de nuestros tiempos, Apolo de nuestras Musas, centro de todas las ciencias y quintaesencia de los mayores ingenios, don Francisco de Quevedo» (f. 41r). El poeta invocado vuelve entonces de entre los muertos para entregarle el vejamen escrito en un papel que el fiscal se encarga de leer. Bajo la autoridad de Quevedo, y recurriendo a la socorrida estructura de desfile tan característica del teatro breve, el autor del vejamen presenta burlescamente a cada uno de los participantes de la academia, que acuden al Parnaso con vistas a diplomarse en poesía. El presidente de la academia, José de Villarroel, aparece así presentado como un esquelético colegial de primer año - sirviéndose del socorridísimo tópico del estudiante hambriento- (f. 44r). De Nicolò Minato, don Ignacio destacó la cojera (ff. 44r-45v) y de Juan Marín, su baja estatura (ff. 45v-46r). En cuanto a Francesco de Tintoribus, se hizo hincapié en su edad avanzada (ff. 47r-48v), mientras que Luis de Heredia fue blanco de burlas por su voz aguda, por ser pobre de versos y porque no llevaba la cabellera postiza que imponía la moda imperante en aquel momento (ff. 48v-49v). De Gilberto Ferri destacó el fiscal su tez blanca y su pelo rubio (ff. 49v-51r); de José de Villarroel el Mozo, el hecho de ser extremadamente flaco y lampiño (ff. 51r-52v). Girolamo Branchi sería patizambo (ff. 52v-54r), Cristoforo Pertusati, pequeño y redondo (ff. 54r-55v), José de Angulo, de cuerpo enjuto y desplumado, con piernas largas y delgadas y con la cara angosta y larga (ff. 55v-57r). El último retrato burlesco - un autorretrato- correspondió a Isidro de Angulo, presentado como calvo, con párpados como alforjas y con una frente larga (ff. 57r-59r). El vejamen se cierra finalmente con una nueva captatio benevolentiae por parte de don Isidro, quien insiste en «la esperanza de lograr el debido perdón de [sus] faltas volviendo a decir que todo se ha dicho en chanza» (f. $59 \mathrm{r})$.

Presenta la academia de Laxenburg, en suma, todas y cada una de las características propias de una academia literaria española de la época ${ }^{38}$, por lo que su celebración da cuenta de un interesante caso de la recepción de la literatura española en la corte de la rama menor de la casa de Austria. De la misma manera, su estudio contribuye a completar el panorama de la producción literaria en lengua castellana del siglo XVII no solo en los distintos territorios que conformaban la Monarquía hispánica, sino también más allá de sus fronteras.

\section{Referencias bibliográficas}

BÈGUE, Alain, Las academias literarias en la segunda mitad del siglo XVII: Catálogo descriptivo de los impresos castellanos de la Biblioteca Nacional de Madrid, prólogo de Aurora Egido, Madrid, Biblioteca Nacional de España (Premio de Bibliografía), 2007.

-, «Academia que se celebró en Palacio en la real presencia de sus Majestades, estando en público el día veinte de febrero de este año de 1700: Sociabilidad palaciega y República de las Letras en las postrimerías del reinado de Carlos II», en Culturas y escrituras entre siglos (del XVI al XXI), ed. Alain Bègue, María Luisa Lobato, Carlos Mata y Jean-Pierre Tardieu,

\footnotetext{
${ }^{38}$ Véase Bègue, 2007, pp. 25-30.
} 
Pamplona, Servicio de Publicaciones de la Universidad de Navarra (Colección BIADIG, Biblioteca Áurea Digital, 17 / Publicaciones Digitales del GRISO), 2013, pp. 45-120.

—, «Literatura cortesana y representación político-religiosa de Carlos II de España: Academia a que dio asunto la religiosa y católica acción que el Rey, nuestro señor, ejecutó el día 20 de enero deste año de 1685 (estudio y edición)», Libros de la Corte, 14, Año 9, PrimaveraVerano, 2017, pp. 7-118.

DE BIN, Umberto, «Leopoldo I imperatore e la sua Corte nella letteratura italiana», Bollettino del Circolo Accademico Italiano di Vienna, Trieste, Anno sociale XXVIII, 1910.

Gresset, Maurice, Pierre Gresser y Jean-Marc DeBARD, Histoire de l'annexion de la Franche-Comté et du pays de Montbéliard, Le Coteau, Horvath, 1988.

HATTAWAY, Janet, "'Music charms the senses...': devotional music in the Triunfos festivos of San Ginés, Madrid, 1656», Capítulo 9 de Devotional music in the Iberian World, 1450-1800. The villancico and related genres, ed. Tess W. Knighton and Álvaro Torrente, Aldershot, Ashgate Variorum, 2007, pp. 219-230.

REYES PEÑA, Mercedes de los, «Una fiesta teatral española en la corte de Viena (1667)», en En torno al teatro del Siglo de Oro. Actas de las jornadas IX-X celebradas en Almería, coord. por Agustín de la Granja, Heraclia Castellón Alcalá, Antonio Serrano Agulló, Almería, Instituto de Estudios Almerienses, 1995, pp. 195-231.

-, «El teatro barroco en las cortes europeas: las representaciones de Fineza contra fineza en Viena (1671) y en Madrid (1717)», en Actes du Congrès International "Théâtre, Musique et Arts dans les Tours Européennes de la Renaissance et du Baroque, ed. Kazimierz Sabik, Varsovie, Éditions de l'Université de Varsovie, 1997, pp. 116-141.

RITTER, Michael, "Man sieht der Sternen König glantzen”: Der Kaiserhof im barocken Wien als Zentrum deutsch-italienischer Literaturbestrebungen (1653 bis 1718) am besonderen Beispiel der Libretto-Dichtung, Wien, Edition Praesens, 1999.

TETTONI, Leone, y F. SALADINI, Teatro araldico, ovvero Raccolta generale delle armi ed insegne gentilizie delle più illustri e nobili casate che esisterono un tempo e che tuttora fioriscono in tutta l'Italia, illustrate con relative genealogico-storiche nozioni, Lodi, C. Wilmant, 1841-1847. 7 vols.

TORSELlini, Horatio (S.I.), Ristretto dell'Historie del mondo, Venecia, Zaccaria Conzatti, 1675.

VAREY, J. E., y N. D. SHERGOLD, «Introducción», en Juan Vélez de Guevara, Los celos hacen estrella, ed. J. E. Varey y N. D. Shergold, con una edición y estudio de la música por Jack Sage, London, Tamesis Books (Colección Támesis, Serie B. Textos, IV), 1970, pp. i-cxviii.

VILLA-URRUTIA, Wenceslao Ramírez de, Relaciones entre España y Austria durante el reinado de la emperatriz doña Margarita, infanta de España, esposa del emperador Leopoldo I, Madrid, Librería de Fernando Fe, 1905.

WeILEN, Alexander von, Zur Wiener Theatergeschichte, die vom Jahre 1629 bis zum Jahre 1740 am Wiener Hofe zur Aufführung gelangten Werke theatralischen Charakters und Oratorien, Wien, Alfred Hölder, 1901. 